\title{
Effects of Sandplay Therapy through Elementary School Visits on the Improvement of Peer Relationships and Social Skills of Children from Low-Income Families
}

\author{
Eun-jin Jung*
}

\begin{abstract}
The purpose of this study was to determine whether sandplay therapy through elementary school visits is effective in improving the social skills and peer relationships of children from low-income families. The subjects were selected from five elementary schools that agreed to participate in the study. Based on the results, the positive effects of sandplay therapy through school visits on the sociality of children from low-income families were verified. The results were consistent with those of previous studies that reported sandplay therapy enhanced children's self-expression and social skills. Further studies would benefit from the inclusion of parental and teacher counseling if the therapy program is to be offered in schools by visiting counselors.

Key words : Visiting counseling service, Social skills, Peer relationships, Elementary school students, Low-income families
\end{abstract}

\footnotetext{
* Corresponding Author: Eun-jin Jung

Sandplay Therapist \& Psychotherapist, Su-won Youth Counseling Center (poohyoungran@hanmail.net)
} 


\section{I . Introduction}

\section{Purpose of the Study}

Most children from low-income families experience a severe sense of difference and inferiority in their sociocultural environments, especially homes and schools, and their feelings of relative deprivation and alienation are likely to find expression as social delinquency and develop into continuous, long-term emotional disturbance (Jeong \& Kim, 2002). Environmental influences, in particular, can lower children's self-confidence, resulting in low self-esteem and passive behavior. This may lead to lack of communication, a decline of clarity in expressing their feelings and, in turn, frequent exposure to stress (Kim, 2008). Failure to engage in effective interaction causes loneliness and frustration due to issues regarding school bullying or maladjustment, which brings about depression and a sense of isolation (Min \& Kwon, 2004; Choi, 2006).

A study of the effects of family financial difficulties on children's adaptive and maladaptive behaviour (Shin, 2008) determined the pathways along which poverty indirectly influences children's behavior through their family's psychological processes. According to the study's results, parents' stress and conflicts resulting from economic strain affect their parenting behavior, thereby leading their children to experience poor peer relationships and socially maladaptive behavior. Such socioeconomic problems are not likely to be overcome at the individual level or through the functioning of the market economy alone. Thus, there have been various attempts to address this, one of which is visiting counseling services.

A visiting counseling service involves the counselors visiting their clients' living spaces. In many cases, children from low-income families are in need of counseling because they are faced with a poor rearing environment or a variety of stress factors resulting from socioeconomic problems. However, they are often neglected without being offered counseling services due to time and financial problems and lack of guardians' care and interest. Accordingly, there is an urgent need for the provision of counseling services to such children by visiting them.

In counseling children from low-income families, the children's problems, activity characteristics, and various environmental influences should be taken into account, instead of simply taking a protective or preventive approach, because they often have more complicated problems than those from ordinary families. Moreover, as they have universal needs related to socio-emotional 
development which is a developmental task during school age, it is necessary to employ a continuous, systematic approach that can improve their psychosocial capabilities (Roh, 2008).

Sandplay therapy is an effective counseling technique for addressing problematic behavior by boosting ego development and self-awareness in childhood. It can act as an effective means of enhancing children's emotions by encouraging them to express their feelings and emotions, thereby strengthening their self-consciousness (Jang, 2008). In addition, it allows children to externalize their problems using sand and various props as play materials, thereby helping them to resolve their conflicts and trauma and develop skillfulness and control (Kalff, 1988).

Moreover, through sandplay therapy sessions, children may attempt internal conversations with themselves, and this enables them to perceive their own thoughts and experiences and, as a result, to solve and recover from problems by themselves (Turner, 2005). Some previous studies based on such therapeutic factors also reported that sandplay therapy improved children's sociality (Kim \& Sun Woo, 2010; Kwon, 2010) and had positive effects on their peer relationships (Shin, 2010).

According to Rubin (1975), children in the early stages of life greatly depend on their parents both physically and psychologically and learn many things from their relationships with parents. However, as they grow up, their competence and independence develop, and they engage in interactions with more fluid and wider-ranging environments, which makes peers important to them. Children feel self-fulfilment by socializing with friends and in their peer groups they express their conflicts and a sense of inferiority. Finding out that other children also have the same problems as they do, they feel relieved and their concerns over health and sense of guilt decrease.

Moreover, they can achieve internal maturity and develop their social adaptability and activity by having harmonious relationships with peers (Kim, et al., 2008; Park \& Kang, 2006). In this sense, environments for children from low-income families may have negative effects on their peer relationships. This is because residential and parenting environments for low-income families do not lead to the sufficient provision of physical and psychological conditions immediately necessary for child development, and also because husband-wife conflicts, mental stress, and low self-esteem as parents resulting from poverty cause parents to neglect protection, education, and nutritional care for their children and fail to perform a proper parental role (Cho \& Chung, 2004). Since it is hard for children from low-income families to receive help from their parents 
or surroundings that reinforce growth factors, such children are in need of external support, such as group activities, which makes up for this problem.

\section{Antecedents}

Programs aimed at children from low-income families have been attempted previously. According to these studies, play-based programs for improving social skills improved the peer relationship behavior of children from low-income, single-mother families (Chung \& Kim, 2006; Lee, et al., 2008), and group art therapy based on cooperative activities enhanced the peer relationships of children from low-income families (Hwang, 2008; Lee, 2004). In addition, music therapy improved the peer relationships of children from low-income families, helping them to competently carry out developmental tasks in childhood (Choi, 2007).

Previous studies that verified the effectiveness of sandplay therapy in improving children's peer relationships had mostly conducted group sandplay therapy programs. A study on the effects of a group sandplay therapy program on the empathy ability and the quality of peer relationships of children with ADHD (attention deficit hyperactivity disorder) tendencies (Shin, 2010) showed that the program positively changed the quality of the children's peer relationships.

Another study which examined the effects of group sandplay programs at child care centers on children's peer interaction (Lee, 2009) revealed that the program had positive effects on the behaviour of the children, who came to express themselves in a positive manner and cooperate with and support each other in the termination stage. In addition, a study on the effects of a group sandplay therapy on anger and peer relationships of neglected children (Kim \& Sun Woo, 2008) showed that the therapy improved their expression of suppressed emotions and increased positive interaction, enabling them to be considerate of others by controlling their own desires.

Nevertheless, no previous study attempted to deal with the psychological problems of children from low-income families through visiting counseling. Thus, this study aimed to provide sandplay therapy for children from low-income families by visiting them, thereby examining its effects on the improvement of their peer relationships and social skills. 


\section{Research Questions}

The purpose of this study was to determine whether sandplay therapy could improve the peer relationships and social skills of elementary school students from low-income families. To this end, the following research questions were established:

Question 1: Is sandplay therapy through elementary school visits effective in improving the social skills of children from low-income families?

Question 2: Is sandplay therapy through elementary school visits effective in improving the peer relationships of children from low-income families?

\section{Methods}

\section{Participants}

The subjects of this study were children from low-income families attending elementary schools in C City. To recruit participants, notices containing the purpose, effects and duration of the program were sent to 39 elementary schools in C City. From five schools that agreed to participate, 35 students from low-income families with problematic behavior were recommended by their homeroom teachers. The recruited participants were divided into the first group of 17 and the second group of 18 . Then from the first group, seven children who had completed four or more sandtrays were finally selected as an experimental group, and from the second group, the same number of children were randomly selected to form a control group.

The first (experimental) group participated in sandplay therapy sessions from November 2009 to February 2010. The second (control) group underwent the therapy program after the program for the first group had been completed, although a pre-test and a post-test were conducted at the same time for both groups. Sandplay therapy was given once a week for 12 weeks, and each session was 40 minutes long. The personal data and general characteristics of the participants are represented in Table 1 below. 
〈Table 1〉Personal Data and General Characteristics of the Participants of the Study

\begin{tabular}{|c|c|c|c|c|c|c|c|}
\hline Group & Participants & Age & Gender & Group & Participants & Age & Gender \\
\hline \multirow{7}{*}{$\begin{array}{l}\text { Experimental } \\
\qquad \begin{array}{l}\text { Group } \\
(n=7)\end{array}\end{array}$} & A & 9 & Male & \multirow{7}{*}{$\begin{array}{l}\text { Control } \\
\text { Group } \\
(n=7)\end{array}$} & $\mathrm{H}$ & 8 & Male \\
\hline & B & 8 & Male & & I & 8 & Male \\
\hline & $\mathrm{C}$ & 7 & Male & & $\mathrm{J}$ & 7 & Female \\
\hline & $\mathrm{D}$ & 7 & Male & & $\mathrm{K}$ & 9 & Male \\
\hline & $\mathrm{E}$ & 8 & Male & & $\mathrm{L}$ & 9 & Female \\
\hline & $\mathrm{F}$ & 9 & Female & & M & 7 & Male \\
\hline & G & 9 & Male & & $\mathrm{L}$ & 8 & Male \\
\hline
\end{tabular}

\section{Research Process}

This study employed the pre- and post-test design with the purpose of verifying the effectiveness of sandplay therapy in improving the peer relationships and social skills of elementary school students from low-income families. After the recruitment of the subjects, for the pre-test teachers took part in tests for the social skills and peer relationships of all of the subjects. Afterwards only the first group, the experimental group, received 40-minute sandplay therapy sessions once a week, for 12 weeks from November 2009 to February 2010.

With the consent of the participants, all of the sessions were videotaped and photographed, and the various types of behavior, stories, and reactions they showed during the sessions were recorded. After the completion of 12 sessions, post-tests were carried out using the same questionnaire as the pre-tests in order to verify the program's effectiveness.

\section{Measurement Tools}

\section{1) Peer Relationship Test for Teachers}

To examine changes in the children's peer relationships, the questionnaire that was developed by Petti et al. (1988) and translated and employed by Ma Song-Hee (1994) was used. The test was composed of 25 items employing a five-point scale. A higher point meant a better peer relationship. The reliability coefficient for the entire items, namely the Cronbach a, was .91. 


\section{2) Social Skill Test for Teachers}

To examine the children's social skills, this study employed the scale of Teacher Form Elementary Level, translated by Kwon Se-Eun (2002), of the Social Skill Rating System (SSRS) developed by Gresham and Elliott (1990).

The social skill test for teachers had three sub-dimensions of cooperation, assertiveness, and self-control and consisted of 30 items employing a three-point scale. A higher point indicated a higher level of social skills. The Cronbach a, namely the reliability coefficient for the items was .95 .

\section{Data Analysis}

The mean values, standard deviations, and Cronbach a of the data collected through the preand post-tests were calculated using SPSS 12.0 for Windows in order to analyze the effectiveness of the program. In addition, the Mann-Whitney U-Test, a non-parametric test, was conducted to test the homogeneity between the groups, and Wilcoxon's Rank Sum-Test, another non-parametric test, was carried out to examine the changes after sandplay therapy and compare the two groups.

\section{Results and Analysis}

\section{Comparison of the Homogeneity of Peer Relationships and Social Skill Scores between the Experimental and Control Groups}

The Mann-Whitney U-Test, a non-parametric test, was conducted to determine the homogeneity of pre-test scores for peer relationships and social skills between the experimental and control groups prior to the sandplay therapy sessions. The results are provided in Table 2 .

As shown in Table 2, there was no statistically significant difference between the experimental and control groups in pre-test scores for peer relationships and social skills.

The Mann-Whitney U-Test, a non-parametric test, was carried out to determine the homogeneity of the pre-test scores for each sub-dimension of peer relationship and social skill 
〈Table 2〉 Comparison of the Homogeneity of Peer Relationship and Social Skill Scores between the Experimental and Control Groups

\begin{tabular}{|c|c|c|c|c|}
\hline \multirow{2}{*}{ Test } & \multicolumn{2}{|c|}{ Mean Rank } & \multirow{2}{*}{$U$} & \multirow{2}{*}{$Z$} \\
\hline & Experimental $(n)$ & $\operatorname{Control}(n)$ & & \\
\hline Social Skill Test & 7.07(7) & 7.93(7) & 21.50 & -0.39 \\
\hline Peer Relationship Test & $6.71(7)$ & $8.29(7)$ & 19.00 & -0.70 \\
\hline
\end{tabular}

between the experimental and control groups. As indicated in Table 3, the results showed no significant differences between the two groups in pre-test scores for sociality, leadership, stability, competence, and cooperativeness, which were the sub-dimensions of the peer relationship test. As represented in Table 4, there were no significant differences between the two groups in pre-test scores for cooperation, assertiveness, and self-control, which were the sub-dimensions of the social skill test.

〈Table 3〉 Comparison of the Homogeneity of the Sub-Dimension Scores in the Peer Relationship Test between the Groups

\begin{tabular}{|c|c|c|c|c|}
\hline \multirow{2}{*}{ Sub-Dimension } & \multicolumn{2}{|c|}{ Mean Rank } & \multirow{2}{*}{$U$} & \multirow{2}{*}{$Z$} \\
\hline & Experimental $(n)$ & $\operatorname{Control}(n)$ & & \\
\hline Sociality & $7.50(7)$ & $7.50(7)$ & 24.50 & 0.00 \\
\hline Leadership & $6.43(7)$ & $8.57(7)$ & 17.00 & -0.97 \\
\hline Stability & $6.14(7)$ & $8.86(7)$ & 15.00 & -1.22 \\
\hline Competence & $7.71(7)$ & $7.29(7)$ & 23.00 & -0.20 \\
\hline Cooperativeness & $7.43(7)$ & $7.57(7)$ & 24.00 & -0.07 \\
\hline
\end{tabular}

〈Table 4〉 Comparison of the Homogeneity of the Sub-dimension Scores in the Social Skill Test between the Groups

\begin{tabular}{|c|c|c|c|c|}
\hline \multirow{2}{*}{ Sub-Dimension } & \multicolumn{2}{|c|}{ Mean Rank } & \multirow{2}{*}{$U$} & \multirow{2}{*}{$Z$} \\
\hline & Experimental $(n)$ & Control $(n)$ & & \\
\hline Cooperation & $6.93(7)$ & $8.07(7)$ & 20.50 & -0.52 \\
\hline Assertiveness & $6.86(7)$ & $8.14(7)$ & 20.00 & -0.59 \\
\hline Assertiveness & $7.36(7)$ & 7.64(7) & 23.50 & -0.13 \\
\hline
\end{tabular}


Thus, before the sandplay therapy sessions, the two groups initially had homogeneous conditions regarding the sub-dimensions of peer relationship and social skill, which enabled the program's effectiveness to be verified by examining changes before and after the program.

\section{Effects of Sandplay therapy through School Visits on Peer Relationships of Children from Low-Income Families}

Wilcoxon's Rank Sum-Test, a non-parametric test, was conducted to determine the effects of sandplay therapy through school visits on the peer relationships of children from low-income families. The results are represented in Table 5 .

As indicated in Table 5, the children in the experimental group showed more improvements than those in the control group in scores for leadership, competence, and cooperativeness among the sub-dimensions of peer relationship, while the two groups did not have any differences in scores for the other sub-dimensions, namely sociality and stability. For the experimental group, the mean score increase for leadership was about 3.43 points between the pre-test $(M=7.57)$ and the post-test $(M=11.00)$, and the difference between the pre- and post-tests was significant $(Z=-2.06, p<.05)$.

In contrast, the control group did not see significant differences between the pre- and post-tests. As for competence, the experimental group show a mean score increase of about 1.86 points between the pre-test $(M=7.71)$ and the post-test $(M=9.57)$, and showed a statistically significant difference between the pre- and post-tests $(Z=-2.26, p<.05)$, whereas the control group did not see a significant difference between the pre- and post-tests. Moreover, for the experimental group, the mean score increase for cooperativeness was about 2.43 points between the pre-test $(M=8.57)$ and the post-test $(M=11.00)$, and the difference between the pre- and post-tests was significant $(Z=-2.06, p<.05)$. In comparison, the control group did not show any significant differences between the pre- and post-tests. 
〈Table 5〉 Comparison of Peer Relationships before and after the Program

\begin{tabular}{|c|c|c|c|c|c|c|c|c|c|c|c|}
\hline \multirow{4}{*}{ Variable } & \multirow{4}{*}{ Group } & & \multirow{4}{*}{$\begin{array}{c}M \\
(S D)\end{array}$} & \multirow{2}{*}{\multicolumn{3}{|c|}{$\begin{array}{c}\text { Negative Rank } \\
\text { Pre-Post }\end{array}$}} & \multirow{2}{*}{\multicolumn{3}{|c|}{$\begin{array}{c}\text { Positive Rank } \\
\text { Pre-Post }\end{array}$}} & \multirow{4}{*}{$Z$} & \multirow{4}{*}{ Tie } \\
\hline & & & & & & & & & & & \\
\hline & & & & \multirow{2}{*}{$\mathrm{N}$} & Mean & Rank & \multirow{2}{*}{$\mathrm{N}$} & Mean & Rank & & \\
\hline & & & & & Rank & Sum & & Rank & Sum & & \\
\hline \multirow{4}{*}{ Sociality } & \multirow{2}{*}{$\begin{array}{c}\text { Experimental } \\
(n=7)\end{array}$} & Pre & $9.14(4.29)$ & \multirow{2}{*}{1} & \multirow{2}{*}{1.50} & \multirow{2}{*}{1.50} & \multirow{2}{*}{5} & \multirow{2}{*}{3.90} & \multirow{2}{*}{19.50} & \multirow{2}{*}{-1.89} & \multirow{2}{*}{1} \\
\hline & & Post & $11.14(3.81)$ & & & & & & & & \\
\hline & \multirow{2}{*}{$\begin{array}{l}\text { Control } \\
(n=7)\end{array}$} & Pre & $8.71(3.25)$ & \multirow{2}{*}{0} & \multirow{2}{*}{0.00} & \multirow{2}{*}{0.00} & \multirow{2}{*}{3} & \multirow{2}{*}{2.00} & \multirow{2}{*}{6.00} & \multirow{2}{*}{-1.63} & \multirow{2}{*}{4} \\
\hline & & Post & $9.29(3.45)$ & & & & & & & & \\
\hline \multirow{4}{*}{ Leadership } & \multirow{2}{*}{$\begin{array}{c}\text { Experimental } \\
\qquad(n=7)\end{array}$} & Pre & $7.57(2.94)$ & \multirow{2}{*}{0} & & & & & & 咩 & 0 \\
\hline & & Post & $11.00(2.10)$ & & & & & & & & \\
\hline & Control & Pre & $8.57(2.15)$ & & & & & & & & \\
\hline & $(n=7)$ & Post & $7.57(0.98)$ & 4 & 0.38 & 13) 0$. & 1 & 1.50 & 1.) 0 & -1.00 & 2 \\
\hline & Experimental & Pre & $8.57(3.95)$ & 1 & 100 & 100 & t & 250 & 140 & 176 & 2 \\
\hline & $(n=7)$ & Post & $12.14(3.98)$ & 1 & 1.00 & 1.00 & 4 & 3.30 & 14.00 & $-1 . / 0$ & 2 \\
\hline & Control & Pre & $10.14(1.57)$ & 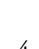 & & & & & & & \\
\hline & $(n=7)$ & Post & $8.86(1.95)$ & 4 & 2.30 & 10.00 & 0 & 0.00 & 0.00 & -1.04 & J \\
\hline & Experimental & Pre & $7.71(3.21)$ & 0 & $\rho \cap 0 \Omega$ & O & ( & 250 & 100 & $6^{*}$ & 1 \\
\hline & $(n=7)$ & Post & $9.57(3.21)$ & 0 & 0.00 & 0.00 & 0 & 3.50 & 21.00 & -2.26 & 1 \\
\hline & Control & Pre & $6.86(1.87)$ & & & & & & & & \\
\hline & $(n=7)$ & Post & $8.57(2.31)$ & 1 & 1.00 & & 4 & 3) 0$. & 14.00 & -1.19 & 2 \\
\hline & Experimental & Pre & $8.57(3.41)$ & 0 & $0 \Omega 0$ & 000 & 5 & 200 & 500 & $206^{*}$ & 1 \\
\hline & $(n=7)$ & Post & $11.00(2.94)$ & 0 & 0.00 & 0.00 & ) & 5.00 & 15.00 & -2.00 & 1 \\
\hline & Control & Pre & $8.71(2.29)$ & & & & & & & & \\
\hline & $(n=7)$ & Post & $8.86(0.90)$ & 2 & $2.2)$ & 4.50 & 2 & $2.1)$ & 5) 0$. & -0.18 & 3 \\
\hline
\end{tabular}

$* p<.05$

3. Effects of Sandplay therapy through School Visits on Social Skills of Children from Low-Income Families

Wilcoxon's Rank Sum-Test, a non-parametric test, was conducted to determine the effects of sandplay therapy through school visits on the social skills of children from low-income families. 
$\langle$ Table 6〉 Comparison of Social Skills before and after the Program

\begin{tabular}{|c|c|c|c|c|c|c|c|c|c|c|c|}
\hline \multirow{4}{*}{ Variable } & \multirow{4}{*}{ Group } & & \multirow{4}{*}{$\begin{array}{c}M \\
(S D)\end{array}$} & \multirow{2}{*}{\multicolumn{3}{|c|}{$\begin{array}{c}\text { Negative Rank } \\
\text { Pre-Post }\end{array}$}} & \multirow{2}{*}{\multicolumn{3}{|c|}{$\begin{array}{c}\text { Positive Rank } \\
\text { Pre-Post }\end{array}$}} & \multirow{4}{*}{$Z$} & \multirow{4}{*}{ Tie } \\
\hline & & & & & & & & & & & \\
\hline & & & & \multirow{2}{*}{$\mathrm{N}$} & & Rank & \multirow{2}{*}{$\mathrm{N}$} & & & & \\
\hline & & & & & Rank & Sum & & Rank & Sum & & \\
\hline \multirow{4}{*}{ Cooperation } & \multirow{2}{*}{$\begin{array}{c}\text { Experimental } \\
\qquad(n=7)\end{array}$} & Pre & $3.57(4.61)$ & \multirow{2}{*}{0} & \multirow{2}{*}{0.00} & \multirow{2}{*}{0.00} & \multirow{2}{*}{6} & \multirow{2}{*}{3.50} & \multirow{2}{*}{21.00} & \multirow{2}{*}{$-2.20^{*}$} & \multirow{2}{*}{1} \\
\hline & & Post & $10.71(7.02)$ & & & & & & & & \\
\hline & \multirow{2}{*}{$\begin{array}{l}\text { Control } \\
(n=7)\end{array}$} & Pre & $3.71(2.69)$ & \multirow{2}{*}{5} & \multirow{2}{*}{3.00} & \multirow{2}{*}{15.00} & \multirow{2}{*}{0} & \multirow{2}{*}{0.00} & \multirow{2}{*}{0.00} & \multirow{2}{*}{$-2.06^{*}$} & \multirow{2}{*}{2} \\
\hline & & Post & $4.00(3.87)$ & & & & & & & & \\
\hline \multirow{4}{*}{ Assertiveness } & \multirow{2}{*}{$\begin{array}{c}\text { Experimental } \\
\qquad(n=7)\end{array}$} & Pre & $2.57(3.36)$ & \multirow{2}{*}{0} & \multirow{2}{*}{0.00} & \multirow{2}{*}{0.00} & \multirow{2}{*}{6} & \multirow{2}{*}{3.50} & & 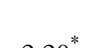 & \\
\hline & & Post & $8.71(5.41)$ & & & & & & 21.00 & -2.20 & 1 \\
\hline & Control & Pre & $2.57(2.30)$ & & & & & & & & \\
\hline & $(n=7)$ & Post & $2.71(3.04)$ & 3 & 2.00 & 6.00 & 1 & 4.00 & 4.00 & -2.37 & 3 \\
\hline & Experimental & Pre & $2.57(3.36)$ & 0 & 000 & $0 \Omega 0$ & 6 & 350 & 100 & $20^{*}$ & 1 \\
\hline & $(n=7)$ & Post & $8.71(5.41)$ & 0 & 0.00 & 0.00 & 0 & 3) 0$. & 21.00 & -2.20 & 1 \\
\hline & Control & Pre & $2.57(2.30)$ & & & & & & & & \\
\hline & $(n=7)$ & Post & $2.71(3.04)$ & 3 & 2.00 & 6.00 & 1 & 4.00 & 4.00 & -2.31 & 3 \\
\hline
\end{tabular}

$* p<.05$

The results are represented in Table 6 .

As indicated in Table 6, after the program, the children in the experimental group showed improvements in their scores for cooperation, assertiveness, and self-control, the sub-dimensions of social skill.

In scores for cooperation, both groups showed significant changes. For the experimental group, the mean score increase between the pre-test $(M=3.57)$ and the post-test $(M=10.71)$ was about 7.14 points, indicating a significant difference between before and after the program $(Z=-2.20$, $p<.05)$. The control group also showed a mean score increase of about 0.29 points between the pre-test $(M=3.71)$ and the post-test $(M=4.00)$, suggesting a significant difference between before and after the program $(Z=-2.06, p<.05)$.

In contrast, significant changes in assertiveness and self-control were only observed in the experimental group. For assertiveness, the experimental group showed a mean score increase of about 6.14 points between the pre-test $(M=2.57)$ and the post-test $(M=8.71)$, indicating a 
significant change between before and after the program $(\mathrm{Z}=-2.20, \mathrm{p}<.05)$, whereas the control group showed no significant change between the pre- and post-tests. For self-control, the experimental group showed a mean score increase of about 6.15 points between the pre-test $(M=4.14)$ and the post-test $(M=10.29)$, indicating a significant change between before and after the program $(\mathrm{Z}=-2.11, \mathrm{p}<.05)$, whereas the control group showed no significant change between the pre- and post-tests.

\section{Discussion}

\section{Summary}

The purpose of this study was to determine whether sandplay therapy through elementary school visits is effective in improving the social skills and peer relationships of children from low -income families. The subjects of this study were selected from five elementary schools in C City that agreed to participate in the study. A total of 35 students from low-income families with problematic behavior were initially recommended as participants by their homeroom teachers. The students were subsequently divided into a group of 17 for the first round of sandplay therapy and another group of 18 for the second round of sandplay therapy. The first group that received sandplay therapy was selected as candidates for the experimental group in this study, and the second group that participated in therapy was selected as candidates for the control group. Eventually seven children from the first group who had completed four or more sandtrays formed the experimental group, while the same number of children was randomly selected from the second group to form the control group.

This study employed the pre- and post-test design. After the recruitment of participants, the teachers were instructed to participate in a pre-test on the children's social skills and peer relationships. The experimental group subsequently received 40-minute sandplay therapy sessions once a week for 12 weeks from October 2009 to February 2010. With the consent of the participants, each session was videotaped and photographed, and the children's behavior, conversations, and reactions during the sessions were recorded. After the completion of the program, a post-test was conducted using the same questionnaire as the pre-test, and the results 
of the two tests were analyzed using the Mann-Whitney U-Test and Wilcoxon's Rank Sum-Test, which are non-parametric tests.

\section{Discussion}

Through the above process, the following results were obtained: First, as for the effectiveness of sandplay therapy at schools in improving the peer relationships of children from low-income families, the experimental group showed no significant changes in sociality and stability (two of the sub-dimensions of peer relationship), but showed significant improvements in leadership, competence, and cooperativeness. For leadership, the mean score increase was about 3.43 points between the pre-test $(M=7.57)$ and the post-test $(M=11.00)$, which was a statistically significant change $(Z=-2.06, p<.05)$. For competence, the mean score increase was about 1.86 points between the pre-test $(M=7.71)$ and the post-test $(M=9.57)$, which was a significant change $(Z=-2.26, p<.05)$. Moreover, for cooperativeness, the mean score increase was about 2.43 points between the pre-test $(M=8.57)$ and the post-test $(M=11.00)$, which was a significant change before and after the program $(Z=-2.06, p<.05)$.

The control group, however, did not show any significant changes in scores for the subdimensions of peer relationship. These results suggest that sandplay therapy is effective in enhancing leadership, competence, and cooperativeness in children from low-income families in their peer relationships. The results were consistent with those of a study on the effects of sandplay therapy on children with ADHD tendencies (Shin, 2010), which revealed that sandplay therapy improved their peer relationships. The results also corresponded to those of a study on the effects of sandplay therapy on neglected children (Kim \& Sun Woo, 2010), which showed that the therapy enhanced the subjects' peer relationships.

Second, according to the results of the test on the effects of sandplay therapy on the improvement of social skills of children from low-income families, the experimental group showed significant improvements in all of the sub-dimensions of social skill after the program. For cooperation, the mean score increase was about 7.14 points between the pre-test $(M=3.57)$ and the post-test $(M=10.71)$, which is a significant change $(Z=-2.20, p<.05)$. For assertiveness, the mean score increase was about 6.14 points between the pre-test $(M=2.57)$ and the post-test $(M=8.71)$, which is a significant change $(Z=-2.20, p<.05)$. For self-control, the mean score 
increase was about 6.15 points between the pre-test $(M=4.14)$ and the post-test $(M=10.29)$, which is a significant change $(Z=-2.11, p<.05)$.

In contrast, the control group showed an significant improvement only in cooperation $(Z=-2.06, p<.05)$, with the mean score increase being about 0.29 between the pre-test $(M=3.71)$ and the post-test $(M=4.00)$, and showed no significant changes in scores for the other sub-dimensions. These results suggest that sandplay therapy is effective in improving the social skills of children from low-income families. The results are consistent with those of previous studies that reported play therapy enhanced children's social skills (Jeong \& Kim, 2002; Kwon \& Lee, 2007; Lee, et al., 2008) and that of a study that revealed sandplay therapy improved children's sociality (Kwon, 2010). They also correspond to those of the study that showed sandplay therapy improved the self-expression of institutionalized children (Lee, 2009; Kwon \& Yi, 2002).

\section{Conclusion}

Based on the above results, the positive effects of sandplay therapy through school visits on the social skills and peer relationships of children from low-income families have been verified. Nevertheless, the limitations of this study and suggestions for future studies are as follows.

First, this study focused on elementary school students from low-income families, but the results should not be generalized and applied to the entire spectrum of low-income families due to the small number of the participants. Future studies should survey larger samples.

Second, there was a need for parental counseling as part of the program because elementary school students are likely to be greatly influenced by their parents. However, there were some difficulties in conducting on-going parent counseling because of the environmental or economic issues of low-income parents. Therefore, future studies need to take an approach that can help children from low-income families to be supported and nurtured by their parents over the course of the therapy program.

Third, given that teachers were directed to complete questionnaires about their students' social skills and peer relationships, it is assumed that the teachers' perceptions of the children and therapy influenced their answers to the questionnaire. Promoting teachers' understanding 
of children and therapy through teacher counseling should facilitate the positive effects of therapy.

Fourth, the therapy was limited to 12 sessions due to the lack of space in the schools and spare time for therapy. Institutional support is necessary to invigorate sandplay therapy programs in schools by visiting counselors.

In conclusion, this study demonstrated the positive effects of sandplay therapy in improving the social skills and peer relationships of children from low-income families. However, future studies would benefit from the inclusion of parental and teacher counselling if the therapy program is to be offered in schools by visiting counselors.

\section{References}

Cho, J.-E., \& Chung, O.-B. (2004). The Relationship between the Fathers' Child-Rearing Behaviors and Involvements and Children's Stress Coping Behaviors. The Korean journal of buman development, 11(3), $135-155$.

Choi, A.-N. (2007). The Effects of Music Therapy on the Aggressiveness and Self-Esteem of Children from Various-Income Group (Emphasis on Low- and Middle- Income Family Children). Journal of Emotional \& Behavioral Disorders. 23(3), 129-163.

Choi, M.-K. (2006). A Effect of Individual and Group Play Therapy: A Case Study of a boy who has difficulty in peer interaction. Korean Journal of Play Therapy, 9(1), 121-132.

Chung, Y.-J., \& Kim, K.-W. (2006). The Influence Having Peer Relationships and Affectionate Relationships with the Mother Had on Children`s Loneliness. The Korean Journal of Counseling and Psychotherapy, 18(1), 217-232.

Hwang, J.-H. (2008). A Case Study on the Effect of Art Therapy Improvement of the Self-Esteem and Peer Relationship from Single-parent Family's Child. Korean Journal of Art Therapy, 15(4), 821-838.

Jang, M.-K. (2008). Comparison of Sandplay Therapy and Play Therapy. The Journal of Child Education. 17(2). 243-254.

Jeong, H.-H., \& Kim, M.-K. (2002). The Effect of Group Art-Therapy on Low-Income Children's Stress Reduction. Journal of Korean council for children's rights, 6(1), 163-186.

Kalff, D. M. (1988). Sandplay: A Psychotherapeutic approach to the psyche. Cloverdale, CA: Temenos 
Press. (Original work published in 1980)

Kenneth H. Rubin. (1975). Day care and early childhood education in Ontario: A Canadian perspective. Child and Youth Care Forum, 4(3), 150-155.

Kim, D.-H., \& Sun Woo, H. (2010). A Qualitative Research on Sand Play Therapy for Neglected Children in Low-Income Brackets. Korean Journal of Play Therapy, 13(3), 23-38.

Kim, H.-E. (2008). Effects of Group Art Therapy on Self-Esteem and Interpersonal Skills of GongBuBang Children from Low-Income Families. Journal of Arts Psychothreapy, 4(2), 175-197.

Kim, M.-S., Kim. G.-S. \& Lee, M.-S. (2008). The Comparative Study on Developing and Making an Application the Comprehensive Intervention Program for Low-Income Young Children. Journal of Korean council for children's rights, 12(2), 161-187.

Kwon, M.-S. (2010). The study of the common significance and the process of a change in self-esteem and interaction that is shown in the sand-play therapy when the attachmentdeficient children with mother. Korean Journal of Interdisciplinary Therapy, 2(2), 49-71.

Kwon, O., \& Lee, J.-D. (2007). A Study of Poverty Preschool Children's Sociality -Focused on Group Social Competence Programs. Korean Journal of Child Psychotherapy, 2(1), 65-78.

Kwon, S.-E., \& Yi, S.-H. (2002). Differences between institutionalized and Home - reared Children in Social Skills and Affective Perspective Taking. Korean Journal of Child Studies, 23(2), 107-120.

Lee, J.-S., Jung, E-S., Kim, K.-S., Park, J.-Y., Park, H.-A., \& Seo, B.-R. (2008). The Effects of Social Skills Training Group-Counseling Program on the Social ability and Aggression of preschooler in low-income families. Korean Journal of Child Psychotherapy, 3(2), 19-40.

Lee, K.-M. (2004). Improvement of Peer Relationship and Sociality to the Deprived Children by Art Therapy. Journal of Emotional \& Behavioral Disorders, 20(1), 357-372.

Lee, Min-Hee. (2009). The Effects of a Group Sand Play Program in Childcare Institution on Young Children's Peer Interaction. Child Psychology and Education, Graduate School of Myongji University.

Ma, Song Hee. (1994). Prediction of Children's Social Acceptance Following Transition from Kindergarten Elementary School. Child Studies in Diverse Contexts. 15(1), 159-172.

Noh, S.-D. (2008). Bringing counseling to clients. Seoul: Hakji-sa.

Park, R.-G., \& Kang, W.-S. (2006). Emotional and Behavioral character of low-Income class Children. Korean Journal of Child Psychotherapy, 1(1), 1-23.

Shin, J.-H. (2008). The Moderating Effect of Self-Esteem, Self-Control and the Environment Variables about the Problem Behavior of Children in Low-Income Family. Doctoral dissertation. Graduate School of Sookmyung Women's University. 
Eun-jin Jung / Effects of Sandplay Therapy through Elementary School Visits on the Improvement of Peer Relationships and Social Skills of Children from Low-Income Families

Shin, Jin-Won. (2010). The Effect of Group Sandplay Therapy Program for Empathy Ability and Peer Relationship of Children with Tendency of ADHD. Master thesis Graduate School of Myongji University.

Turner, B. (2005). The Handbook of Sandplay Therapy. Cloverdale, CA: Temenos Press. 